An admirable accomplishment indeed that could stimulate Imco and others involved in maritime safety.

[Mr. Breedveld served for many years as a skipper in the international Rhine trade and so gained wide experience with the rules and regulations of this important European inland waterway. He is now attached as an instructor for radar training to the Rotterdam inland waterway school that offers educational courses for obtaining a Rhine river skipper certificate. He has introduced many innovations into inland waterway radar training. Ed.]

\title{
Yaw Angles and Coriolis
}

\section{P. H. Tanner}

ANNEVELD ${ }^{1}$ has shown that drift angle due to coriolis may be appreciable in the case of large vessels operating in the middle and higher latitudes. Unfortunately the hydrodynamic information on which he bases his equations is not complete, leading to a false idea of the magnitude of the effect at normal ship operating speeds.

It would be preferable to define the lateral force as

where

$$
Y=Y^{\prime}(\beta) \frac{1}{2} \rho V^{2} L H
$$

$Y=$ lateral force on the vessel

$\rho=$ water density

$V=$ ship velocity

$L=$ ship length

$H=$ ship draught

$\beta=$ angle of yaw

$Y^{\prime}(\beta)=$ a coefficient which is a function of $\beta$, and perhaps also of the geometrical properties of the ship hull.

Then we can write the equation for undeflected motion of the vessel relative to the Earth's surface as

$$
Y^{\prime}(\beta) \frac{1}{2} \rho V^{2} L H=2 \rho C_{B} L B H V \omega \sin \phi
$$

or

$$
\beta=Y^{\prime-1}\left(\frac{4 C_{\mathrm{B}} B \omega \sin \phi}{\mathrm{V}}\right)
$$

where

$$
\begin{aligned}
C_{\mathrm{B}} & =\text { ship block coefficient } \\
B & =\text { ship beam } \\
\omega & =\text { Earth angular velocity } \\
\phi & =\text { latitude }
\end{aligned}
$$

Experimental results giving values of $Y^{\prime}(\beta)$ have been obtained by towing ship models at fixed angles of yaw and these may be found in the published literature on the steering of ships. 
For the numbers given below the writer has used the work of Norrbin 2 and Martin, ${ }^{3}$ since these were immediately accessible to him: both these references carry extensive bibliographies, and further work has appeared since.

It would appear that for most practical purposes it is possible to fit the experimental results for a given model with a curve of the form

$$
Y^{\prime}(\beta)=a \beta+b \beta^{n}
$$

In simplified terms, the non-linear term represents the 'stagnation pressure force' with which a stationary ship resists attempts to push it sideways through the water. The linear term derives from the circulation 'lift' produced by the hull of the vessel, acting in this case like the keel of a yacht-or the flying surfaces of an aircraft. That this is so can be seen from the values of a given below which increase with increasing 'aspect ratio' $(H / L)$ and decrease with increasing 'thickness/chord ratio' $(B / L)$.

For small values of $\beta$ ( $<\pi / 20$ say) the non-linear term becomes sufficiently small to be neglected.

(3) then becomes

$$
\beta=\frac{4 \omega \sin \phi}{a} C_{\mathrm{B}} \frac{B}{V}
$$

Comparison of this with Anneveld's equations (6) and (7) shows that he has in effect neglected the linear term which predominates at the small values of $\beta$ which are under discussion.

Unfortunately the published results available to the writer are for warshiptype vessels of fine form. However, the effect of block coefficient should not be very great-one would expect to see the figures for a full bodied vessel lying well within $\pm 5^{\circ}$ per cent of the values below.

With this qualification approximate values for $a$, based on the references given above, are suggested in the following table, which is for a single value of Froude Number, $V / \sqrt{ }(g L)$, of about 0.25 .

\begin{tabular}{r|ccc}
\multicolumn{1}{c}{$L / H=$} & 12 & 20 & 30 \\
\cline { 2 - 5 } & \multicolumn{1}{l}{$L$ a (for $\beta$ in radians) } & & \\
5 & 0.22 & 0.13 & \\
7 & 0.26 & 0.15 & 0.13 \\
10 & & 0.16 & 0.13
\end{tabular}

Reworking Anneveld's examples using the above we obtain

\begin{tabular}{c|rrrrrr|c} 
Example & $V(\mathrm{kt})$ & $\left({ }^{\circ}\right)$ & $B(\mathrm{~m})$ & $L / B$ & $L / H$ & $\beta$ & Anneveld $\delta$ \\
\hline 3 (b) & 21 & 50 & 73 & $6(?)$ & $12(?)$ & $4 \cdot 0$ & $6: 8$ \\
(c) i & 10 & 50 & 73 & $6(?)$ & $12(?)$ & $0 \cdot 8$ & $2 \cdot 9$ \\
ii & 8 & 50 & 20 & $7 \cdot 5$ & $15(?)$ & $0 \cdot 25$ & $1 \cdot 7$ \\
(d) & 6 & 50 & 73 & 6 & 12 & $1 \cdot 3$ & $4 \cdot 0$ \\
(e) & 20 & 50 & 73 & 6 & 12 & $0 \cdot 4$ & $2 \cdot 0$
\end{tabular}

It would appear that from the point of view of en route navigation there is not much cause for concern-unless ship beams increase still further. However, it should be pointed out that the above figures are for the fully loaded tanker. In 
the light condition its draught may well be halved, resulting in $a$ being reduced by a possible 40 per cent, producing a 70 per cent increase in $\beta$.

The argument in case 3 (c) is not easy to follow. Presumably the contention is that two vessels whose centre-lines are exactly parallel will in fact be on courses converging by an angle of $0: 5$. If the ships are so close that this is going to make a difference their masters will no doubt be using other more sensitive variables than ship's heading to decide the possibility of collision.

There remains the $1 \mathrm{kt}$ docking case in example $3(\mathrm{~b})$. The value of $\beta$ is likely, now, to be outside the linear range. This can be dealt with by rewriting (3) to give

$$
Y^{-1}(\beta)=\frac{4 C_{\mathrm{B}} B \omega \sin \phi}{V}
$$

Putting in the numbers, $Y^{-1}(\beta)=0.03$ I for this case, Martin gives results for a ship of $L / H=12.74$ and $B / H=1.85$ at a Froude Number of 0.16 which is close to the characteristics of our ship. Entering a value of the lateral force function into this curve gives a value of $\beta=6: 9$, or a drift speed of $0.12 \mathrm{kt}$ which corresponds well with Anneveld's figure.

The picture changes, however, if we consider the light ship case. In round figures, $L / H$ will be doubled. Martin has results for $L / H=25.42$ and $B / H=2 \cdot 92$. This is a narrower vessel, but the effect of beam is not great at this low aspect ratio. Using this curve $Y^{\prime}(\beta)=0.031$ corresponds with a value of $\beta=10^{\circ}$. The resulting drift speed is $0.18 \mathrm{kt}$-just the critical value quoted by Anneveld. Alternatively, if the ship is brought alongside a quay with no drift, one end of the $440 \mathrm{~m}$ vessel will be $77 \mathrm{~m}$ further out than the other. This is going to make life interesting for the terminal operators.

\section{REFEREN CES}

1 Anneveld, J. C. (1971). Mammoth vessels and coriolis force. This Journal, 24, 50. See also Lewison, G.R.G. This Journal, 24, 252.

2 Norrbin, N. H. (1960). A study of course keeping and manœuvring performance, Publication of the Swedish State Shipbuilding Experimental Tank No. 45, 1960.

3 Martin, M. (196I). Analysis of the lateral force and moment caused by yaw during ship turning, Davidson Laboratory Report R-792, March 1961.

\section{Terrain Clearance During Descent and Approach}

\section{J. D. Proctor}

InTRODUCTION. The purpose of the descent and approach is to move the aircraft from the cruise to final approach while keeping within the proper envelopes of speed, acceleration, rate of descent, adherence to A.T.C. clearances, avoidance of bad weather and clearance from terrain and obstructions and other visible aircraft. Man carries out this task, at least until the ILS glide slope is captured. The methods used are not as thorough as the programme an electronic computer 